\title{
Pathways of trunk neural crest cell migration in the mouse embryo as
} revealed by vital dye labelling

\author{
GEORGE N. SERBEDZIJA ${ }^{1, *}$, SCOTT E. FRASER ${ }^{2}$ and MARIANNE BRONNER-FRASER ${ }^{1}$ \\ ${ }^{1}$ Department of Developmental and Cell Biology, Developmental Biology Center, and ${ }^{2}$ Department of Physiology, and Biophysics, California \\ College of Medicine, University of California, Irvine, CA 92717, USA
}

* Author for reprint requests

\begin{abstract}
Summary
Analysis of neural crest cell migration in the mouse has been difficult due to the lack of reliable cell markers. Recently, we found that injection of DiI into the chick neural tube marks premigratory neural crest cells whose endfeet are in contact with the lumen of the neural tube (Serbedzija et al. Development 106, 809-819 (1989)). In the present study, this technique was applied to study neural crest cell migratory pathways in the trunk of the mouse embryo. Embryos were removed from the mother between the 8 th and the 10th days of development and DiI was injected into the lumen of the neural tube. The embryos were then cultured for 12 to $24 \mathrm{~h}$, and analyzed at the level of the forelimb. We observed two predominant pathways of neural crest cell migration: (1) a ventral pathway through the rostral portion of the somite and (2) a dorsolateral pathway between the dermamyotome and the epidermis. Neural crest cells were observed along the dorsolateral pathway throughout the period of migration. The distribution of labelled cells along the ventral pathway suggested that there were two overlapping phases of migration. An early ventro-
\end{abstract}

\section{Introduction}

In vertebrates, the neural crest is a population of cells that migrates extensively throughout the embryo and gives rise to a variety of neuronal and non-neuronal cell types (Hörstadius, 1950; Weston, 1970; Le Douarin, 1982). In avians, experiments using chick-quail chimeras or the HNK-1 antibody to identify neural crest cells indicate that trunk neural crest cells migrate along two primary pathways (Weston, 1963; Le Douarin, 1973): (1) a dorsolateral pathway between the dermamyotome and the epidermis, whose cells give rise to pigment cells (Rawles, 1947; Serbedzija et al. 1989), and (2) a ventral pathway through the rostral portion of each somitic sclerotome (Rickmann et al. 1985; Bronner-Fraser, 1986), whose cells give rise to the dorsal root and sympathetic ganglia, the adrenal medulla, and Schwann cells (Le Douarin, 1982). lateral phase began before $\mathrm{E} 9$ and ended by $\mathrm{E9.5}$; this pathway consisted of a stream of cells within the rostral sclerotome, adjacent to the dermamyotome, that extended ventrally to the region of the sympathetic ganglia and the dorsal aorta. A later ventromedial phase was apparent after E9.5 and continued through E10.5; this pathway consisted of a thin strand of DiI-labelled cells along the lateral surface of the neural tube which later protruded into the rostral sclerotome to form the dorsal root ganglia and Schwann cells. Those embryos injected at later stages contained labelled cells only in dorsal derivatives, suggesting that neural crest derivatives are populated in a ventral-to-dorsal order. While the overall pattern and order of neural crest migration was similar to that previously observed in avians and rats, some details of the timing and trajectories apparently differed, most notably the timing of neural crest migration along the dorsolateral pathway.

Key words: neural crest, migration, mouse, DiI.
Ultrastructural studies of mouse embryos have permitted an analysis of the emigration of neural crest cells from the neural tube and their initial stages of migration. These studies have shown that trunk neural crest cells arise along the dorsal midline of the neural tube just after fusion of the neural folds, where they emerge into a cell-free space between the epidermis, somites and neural tube (Erickson and Weston, 1983; Sternberg and Kimber, 1986a,b). The neural crest cells are thought to migrate under the epidermis as well as between the neural tube and somite (Rawles, 1947; Erickson and Weston, 1983; Erickson, 1986). Unfortunately, once neural crest cells reach the dorsal edge of the somite, they are no longer distinguishable from the other cell types in their environment by light or electron microscopy; hence, little is known about the exact pathways or timing of neural crest cell migration in mouse. 
In order to visualize migrating neural crest cells in vivo, several cell marking techniques have been applied successfully in other species. These approaches include the transplantation of marked neural tubes into unmarked hosts (Harrison, 1935; Weston, 1963; Chibon, 1967; Le Douarin, 1973; Sadaghiani and Thiebaud, 1987; Krotoski et al. 1988), microinjection of labelled neural crest cells into unlabelled hosts (Tan and Morriss-Kay, 1986) and immunological staining techniques (Vincent and Thiery, 1984; Rickmann et al. 1985; Bronner-Fraser, 1986; .Erickson et al. 1989). Neural tube transplantations are generally not feasible in mammals because of their in utero development and the difficulties associated with extensive manipulation at stages before and during neural crest cell migration. The HNK-1 antibody, which has been used to identify neural crest cells and their migratory pathway in avians (Vincent and Thiery, 1984; Rickmann et al. 1985; Bronner-Fraser, 1986), does not specifically recognize mouse neural crest cells (Holley and Yu, 1987). While HNK-1 appears to recognize neural crest cells in rat embryos (Erickson et al. 1989), interpretation of any experiments performed with the antibody is hampered by its incomplete specificity for neural crest cells (Vincent and Thiery, 1984; Bronner-Fraser, 1986) and its inability to label all neural crest cells (Teillet et al. 1987; Serbedzija et al. 1989). It has been possible to label and follow the migration of cephalic neural crest cells in both the mouse and the rat by orthotopic microinjection of wheat germ agglutinin labelled neural crest cells (Tan and Morris-Kay, 1986; Chan and Tam, 1988). However, this technique involves extensive manipulation of both the donor neural crest cells and the host embryo, which may alter the migratory behavior in an unpredictable manner. A more direct assay is offered by injection of gold-conjugated wheat germ agglutinin into the amnionic cavity to label premigratory neural crest cells in combination with in vitro culturing methods (Chan and Tam, 1988). The wheat germ agglutinin adheres to cell surface glycoconjugates (Gesink et al. 1983), thereby labelling neural crest cell precursors while they are contiguous with the ectoderm, prior to neural tube closure (Smits-van Prooije et al. 1986). Given that present culturing techniques allow about $24 \mathrm{~h}$ of normal development, use of this technique is restricted to the first day of cephalic neural crest cell migration.

Recently we have developed a technique for labelling premigratory neural crest cells by injecting a solution of the fluorescent carbocyanine dye, DiI, into the lumen of the neural tube (Serbedzija et al. 1989). Because DiI is lipid-soluble and hydrophobic, it is incorporated nearly irreversibly into the plasma membranes of all the cells it contacts (Sims et al. 1974). The dye does not spread from labelled to unlabelled cells, nor does it appear to have any adverse effects on neuronal or neural crest cells (Honig and Hume, 1986; Serbedzija et al. 1989). Therefore, injection of DiI into the neural tube lumen offers a simple means to label specifically only those cells that are in contact with the lumen of the neural tube. By examining the movement of labelled cells away from the neural tube, this technique has allowed a direct analysis of the spatial and temporal patterns of neural crest cell migration in avians (Serbedzija et al. 1989).

Here, we utilize Dil-labelling to analyze neural crest cell migration in the trunk of the mouse. Because intraluminal injection of DiI can be used to label neural crest cells at a variety of developmental stages, this technique circumvents the $24 \mathrm{~h}$ limit imposed by whole embryo culture methods (New, 1973, 1977; Sadler, 1979; Sadler and New, 1981). Combining data from different animals permits an analysis of the overall pattern of trunk neural crest cell migration in the mouse, including the pathways of neural crest cell migration, the duration of neural crest cell emigration from the neural tube, and the temporal order of contributions of neural crest cells to their derivatives.

\section{Materials and methods}

\section{Animal preparation}

Embryos were obtained by mating CD-1 females with BDF-1 males (Charles River) overnight. The presence of a vaginal plug the following morning was taken to indicate pregnancy, and the date that the plug was observed was designated embryonic day 0 (E0). Embryos were removed surgically from anesthetized mothers between E8 and E10.5 (8 to 40 somites, respectively), and placed in dissecting media consisting of $20 \%$ fetal bovine serum (Hyclone), $79 \%$ Dulbecco's modified Eagle's medium (DMEM, Whittaker Bioproducts), and $1 \%$ penicillin-streptomycin L-glutamine mixture (GPS Whittaker Bioproducts) at $37^{\circ} \mathrm{C}$. The embryos were then dissected free of the extraembryonic membranes, taking care not to damage the blood vessels within the membranes. Both the embryo and the extraembryonic membranes were left attached to the placenta for the entire culture period.

\section{Microinjection of dye}

All injections were made with either a $0.25 \%$ solution (weight/volume) in $50 \%$ ethanol of 1,1 -dioctadecyl-3,3,3',3' tetramethylindocarbocyanine perchlorate (DiI; Molecular Probes) or a $0.025 \%$ solution (weight to volume) in $5 \%$ ethanol in $0.3 \mathrm{~m}$ sucrose solution. Prior to use, the dye solution was heated to $37^{\circ} \mathrm{C}$ and centrifuged to remove any crystals that might clog the pipet tip. Both the dye and the micropipets were maintained at $37^{\circ} \mathrm{C}$ during the injections, to prevent cold shock to the embryos. The micropipets were backfilled with the DiI solution and attached to a picospritzer (General Valve). The injection pipet was inserted into the lumen of the neural tube (using a micro-manipulator; Marzhauser) at either the level of the otic vesicle, or at the level of the most recently formed somite. In most cases, enough dye solution was expelled to fill the entire length of the neural tube lumen. In embryos whose posterior and/or anterior neuropore had not yet closed, dye was expelled until it could be seen passing out of the open neuropores.

The potential adverse effects of the injection procedure itself were examined by comparing embryos injected at E9 with DiI in $50 \%$ ethanol with uninjected or saline injection embryos. In transverse sections of embryos incubated for $24 \mathrm{~h}$, no morphological differences were obvious among the three sets of embryos.

\section{Embryo culture}

Embryos, with their extraembryonic membranes and placen- 
tas attached, were placed in $15 \mathrm{ml}$ culture tubes containing $2 \mathrm{ml}$ of culture media consisting of $50 \%$ rat serum, $49 \%$ DMEM, and $1 \%$ GPS. The culture tubes were gassed with $95 \%$ oxygen and $5 \%$ carbon dioxide and rotated at 30 revs $\min ^{-1}$ at $37^{\circ} \mathrm{C}$. Embryos were cultured for either 12 or $24 \mathrm{~h}$ before fixation and sectioning. Embryos cultured for $24 \mathrm{~h}$ were gassed a second time after $12 \mathrm{~h}$ of incubation.

Cultured embryos were compared with embryos allowed to develop to similar stages in utero to ascertain if the culture period itself affected embryonic maturation. Based on the size of the limb buds and the number of somites, embryos cultured up to $24 \mathrm{~h}$ appeared similar to embryos that developed in utero. In transverse sections, both sets of embryos had comparably sized neural tubes and dorsal aortae. Our results agree with previous studies that have shown that cultured mouse embryos develop at normal rates for $24 \mathrm{~h}$ after removal from the mother (New, 1973, 1977; Sadler, 1979; Sadler and New, 1981).

\section{Rat serum collection and preparation}

Adult rats were anesthetized by inhalation of halothane (Fluothane, Ayerst Laboratories Inc.) and decapitated using a guillotine. Blood was collected in serum separation tubes (Vacutainer brand SST tubes, Becton Dickinson), and spun for $30 \mathrm{~min}$ at 3400 revs $\mathrm{min}^{-1}$. The immediate centrifugation in SST tubes pelleted the blood cells, allowing a clear fibrin clot to form in the plasma layer. The serum was then decanted away from the clot and stored at $-70^{\circ} \mathrm{C}$.

\section{Histology}

Embryos were fixed by immersion in $4 \%$ paraformaldehyde/ $0.25 \%$ glutaraldehyde in $0.1 \mathrm{~m}$ phosphate buffer (PB) overnight at $4^{\circ} \mathrm{C}$. Embryos were prepared for cryostat sectioning by washing in $0.1 \mathrm{~m} \mathrm{~PB}$ for $1 \mathrm{~h}$, and followed by soaking them in a $15 \%$ sucrose solution for $8-12 \mathrm{~h}$ at $4^{\circ} \mathrm{C}$. They were embedded in $15 \%$ sucrose and $7.5 \%$ gelatin (Oxoid), rapidly frozen in liquid nitrogen and serially sectioned on a cryostat (AO Reichert Histostat) at 30 microns. Sections were mounted in $\mathrm{Gel} /$ mount (Biomeda Corp.) and covered with glass coverslips. The sections were viewed immediately on an epifluorescence microscope through a rhodamine filter set to visualize the Dil. The overall pattern of the Dil-labelling remained relatively stable for 1 to 2 days; however, fine detail was lost within $2-3 \mathrm{~h}$.

\section{Results}

Premigratory mouse neural crest cells were labelled by injection of DiI into the lumen of the neural tube. At the time of our injections, the dorsal neural tube is a pseudostratified epithelium (Erickson and Weston, 1983; Sternberg and Kimber, 1986) in which premigratory neural crest cells maintain an attachment to the lumen of the neural tube. Because of this, intraluminal injections of DiI label the premigratory neural crest cells along with other neural tube cells. Because culture techniques allow only $24 \mathrm{~h}$ of normal development, it was not possible to label neural crest cells early and follow them over extended periods of development. To circumvent this difficulty, we have labelled different embryos at half day intervals and incubated them for 12 or $24 \mathrm{~h}$, so that all developmental stages between E8.5 to E11 were examined. Table 1 presents the injection and fixation times for all embryos used in this study, lists the total number of embryos examined at each stage, and summarizes the results. All observations were made at the level of the forelimb (somites 8-12) and are organized below by stage of injection.

\section{Injection at E8 (Table 1: exp. 1 and 2)}

Embryos injected at E8 (8-12 somites) and incubated for $12 \mathrm{~h}$ contained DiI-labelled cells in the neural tube exclusively. This confirmed the ability of the technique to label only cells in contact with the lumen of the neural tube. Transverse sections of E8 embryos incubated for $24 \mathrm{~h}$ (approximately 20 somites), showed DiIlabelled cells between the dorsal neural tube and the epidermis (Fig. 1A), as well as in the cell-free space bordered by the epidermis, the somites and the neural tube (termed the 'dorsal wedge'). In longitudinal sections, the Dil-labelled cells did not appear to have any segmental organization, but instead were present at the levels of both the rostral and caudal halves of the somites.

Table 1. Summary of experiments and results

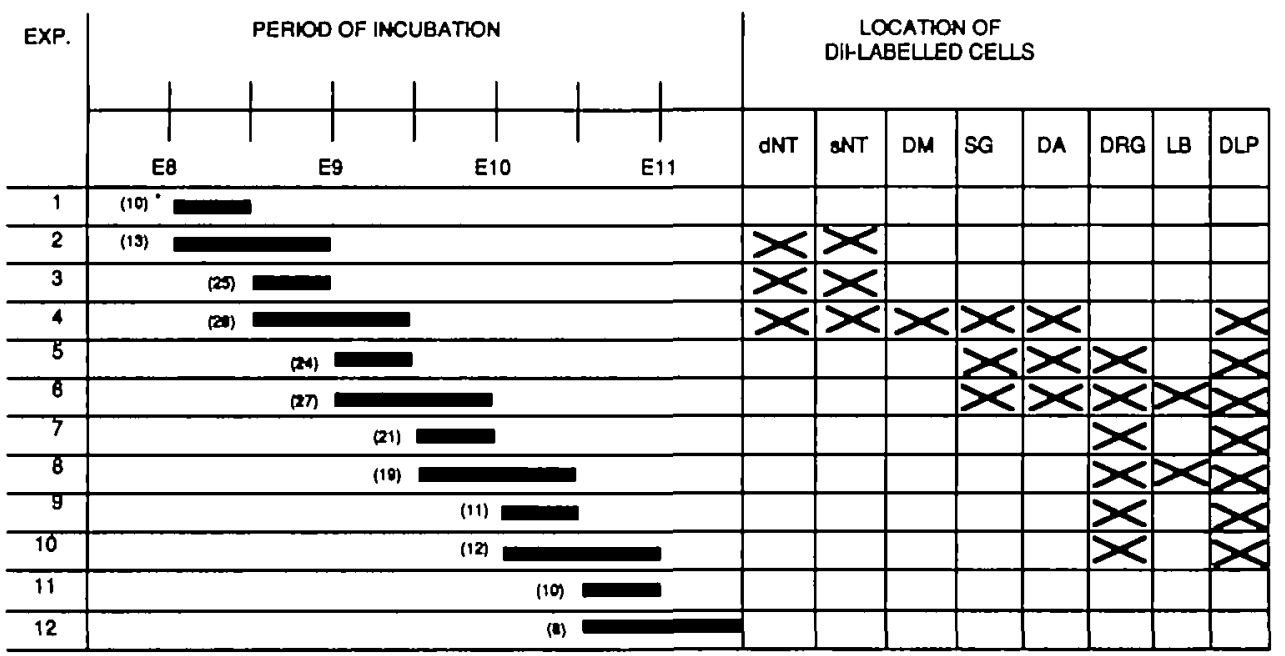

$\mathrm{dNT}=$ Dorsal surface of the neural tube $\mathrm{sNT}=$ Space between the somite and the neural tube

$\mathrm{DM}=$ Medial surface of the dermamyotome SG = Sympathetic ganglia

$\mathrm{DA}=$ Region around the dorsal aorta

$\mathrm{LB}=$ Limb bud

DLP $=$ Dorso-lateral pathway

* Number of embryos in each experiment 
Injection at E8.5 (Table 1: exp. 3 and 4)

In transverse sections of embryos injected at E8.5 (13-16 somites) and incubated for $12 \mathrm{~h}$, many DiIlabelled cells were located between the dorsal neural tube and the epidermis, as well as in the cell-free space of the dorsal wedge (Fig. 1B). In longitudinal sections, DiI-labelled cells had no obvious segmentation to their rostrocaudal distribution at this stage.

Transverse sections through embryos incubated for $24 \mathrm{~h}$ after injection contained DiI-labelled cells extending from dorsal of the neural tube to ventral near the dorsal aorta. Similar to embryos incubated for $12 \mathrm{~h}$, DiI-labelled cells were observed in the dorsal wedge. Other DiI-labelled cells were observed in the dorsal portion of the somitic sclerotome between the neural tube and the medial edge of the dermamyotome, as well as between the dermamyotome and the epidermis (Fig. 1D). In addition to these dorsally positioned cells, 10-20 DiI-labelled cells per section were observed further ventrally within the rostral sclerotome, forming a crescent adjacent to the dermamyotome (Fig. 1C and D). Another one to five DiI-labelled cells per section were observed further ventrad in the region of the sympathetic ganglia and dorsal aorta. In longitudinal section, the DiI-labelled cells within the somitic mesenchyme were observed exclusively in the rostral half of each segment (Fig. 1E). In contrast, labelled cells between the dermamyotome and epidermis did not appear to have a segmental distribution.

\section{Injection at E9 (Table 1: exp. 5 and 6)}

In sections through embryos incubated for $12 \mathrm{~h}$ after injection, DiI-labelled cells were observed on the lateral surface of the dermamyotome, immediately under the epidermis (Fig. 1F). DiI-labelled cells also were observed in a thin stream along the lateral surface of the neural tube, extending from the dorsal portion of the neural tube to the level of the ventral motor root (Fig. 2A and B). It was not clear whether these cells were located within or adjacent to the rostral sclerotome, but they were not observed at the level of the caudal portion of the somites. In addition, individual or small clusters of DiI-labelled cells were observed in ventral portion of the sclerotome (Fig. 2A), the region of the sympathetic ganglia and at the level of the dorsal aorta.

$24 \mathrm{~h}$ after injection, embryos contained numerous DiI-labelled cells that appeared to be intermixed with the somitic sclerotome cells in the region of the forming dorsal root ganglia (Fig. 2C and D). DiI-labelled cells were also present in the sympathetic ganglia (Fig. 2C). Similar to embryos incubated for $12 \mathrm{~h}$, only a small number of Dil-labelled cells were observed around the dorsal aorta. In addition, 5 to 10 well-separated DiIlabelled cells were found in each forelimb (Fig. 2B). By studying serial sections, it was clear that these cells were spread throughout the forelimb, preceding the motor axons.

In contrast to embryos injected at E8.5, none of the embryos injected at E9 contained labelled cells in the
Fig. 1. Sections through embryos labelled with DiI. (A) Transverse section of an embryo injected at E8 and incubated for $24 \mathrm{~h}$; Dil-labelled neural crest cells (arrows) began to appear on the dorsal surface of the neural tube (NT). In the more ventral regions of the embryo, Dillabelling was seen exclusively in the neural tube.

(B) Transverse section of an embryo injected at E8.5 and incubated for $12 \mathrm{~h}$; DiI-labelled neural crest cells were present in the cell-free space (arrows) bordered by the neural tube (NT), the adjacent somite (S) and the ectoderm (the dorsal wedge). (C) Transverse section of an embryo injected at E8.5 and incubated for $24 \mathrm{~h}$; A stream of individual DiI-labelled cells (arrows) was observed in the rostral sclerotome immediately adjacent to the medial surface of the dermamyotome (DM). Labelled cells were also present on the dorsal surface of the neural tube (NT), in the cell-free space (arrowhead) and along the dorsal lateral pathway (long arrow). (D) Transverse section of an embryo injected at E8.5 and incubated for $24 \mathrm{~h}$; Dil-labelled cells were present in the dorsal wedge (arrow heads) and along the dorsal lateral pathway (long arrow). In addition, labelled cells were observed adjacent to the dermamyotome (DM), within the rostral sclerotome and at the level of the sympathetic ganglia (SYM; arrows). (E) Longitudinal section at the level of the forelimb through an embryo injected at E8.5 and incubated for $24 \mathrm{~h}$; In the region just ventral to the cell-free space, Dil-labelled cells (arrow) were seen entering the rostral (R), but not the caudal (C) portion of the somite. $(F)$ Longitudinal section through the tenth somite of an embryo injected at E9 and incubated for $12 \mathrm{~h}$; DiI-labelled cells following the dorsolateral pathway (arrow) were found on the lateral surface of the dermamyotome (DM), just under the ectoderm.

(Rostrocaudal level of section: $A=$ somite $10, B=$ somite 8 , $\mathrm{C}=$ somite $11, \mathrm{D}=$ somite 9 . A,B,C,D: scale $\mathrm{bar}=125 \mu \mathrm{m}$; $\mathrm{E}$ : scale bar $=100 \mu \mathrm{m} ; \mathrm{F}$ : scale $\mathrm{bar}=75 \mu \mathrm{m})$.

sclerotome immediately adjacent to the dermamyotome.

\section{Injection at E9.5 (Table 1: exp. 7 and 8)}

Transverse sections through embryos injected at E9.5 and incubated for 12 or $24 \mathrm{~h}$ contained DiI-labelled cells in the dorsal root ganglia (Fig. 3A) and the forelimbs, in addition to DiI-labelled motor axons. DiI-labelled cells also were seen on the lateral surface of the dermamyotome. In contrast to embryos injected at earlier stages, embryos injected at E9.5 contained no DiI-labelled cells in the region of the sympathetic ganglia or the dorsal aorta.

\section{Injection at E10 (Table 1: exp. 9 and 10)}

Transverse and longitudinal sections through embryos incubated for 12 or $24 \mathrm{~h}$ after injection contained a few DiI-labelled cells in the dorsal portion of the dorsal root ganglia, and on the lateral surface of the dermamyotome, under the epidermis (Fig. 3B).

\section{Injection at E10.5 (Table 1: exp. 11 and 12)}

Sections through embryos injected at E10.5 contained no DiI-labelled cells external to the neural tube (Fig. 3C). DiI-labelled motor axons were the only labelled objects observed external to the neural tube. 

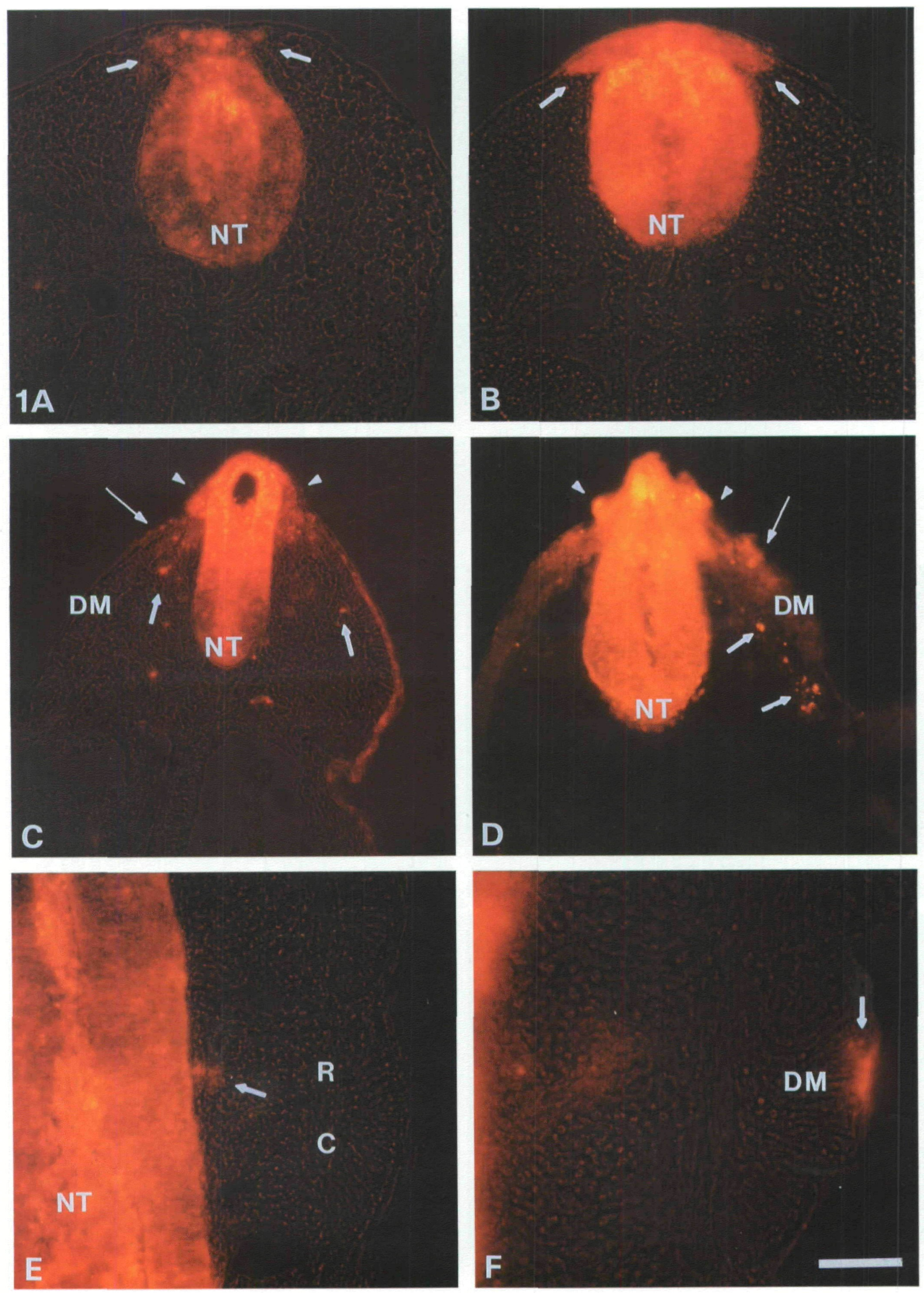

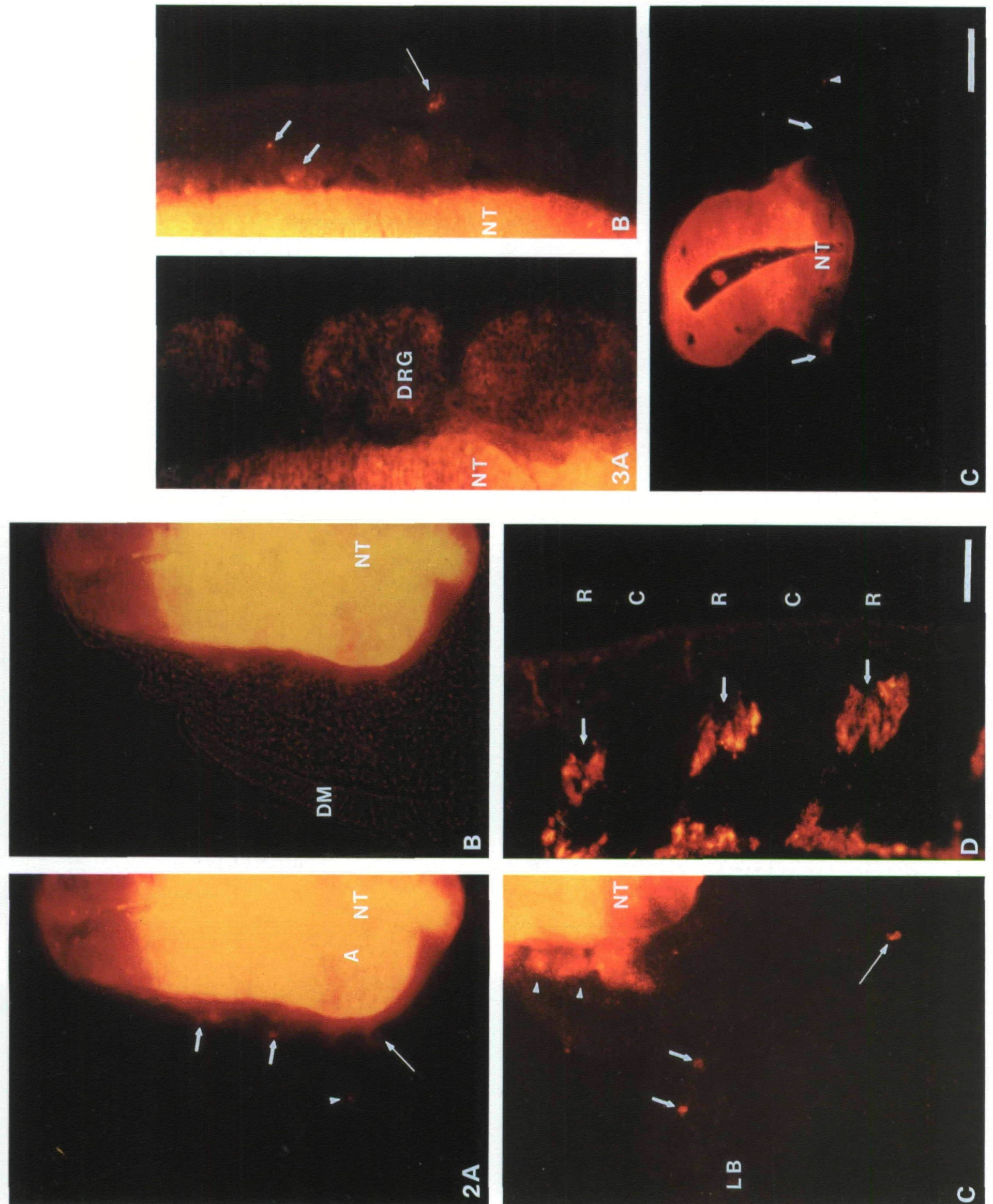

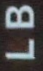


Fig. 2. Transverse and longitudinal sections through embryos injected at E9 and incubated for 12 or $24 \mathrm{~h}$. (A) A transverse section of an embryo incubated for $12 \mathrm{~h}$; A thin stream of Dil-labelled cells (short arrows) was seen along the lateral surface of the neural tube (NT) down to the level of the ventral root (long arrow). In addition, a single labelled cell was observed in the ventral portion of the sclerotome (arrow head). (B) The same section described in A viewed with both brightfield and fluorescence. (C) A transverse section of an embryo incubated for $24 \mathrm{~h}$; Dillabelled cells protruded into the sclerotome in the region of the forming dorsal root ganglia (arrow heads). Dil-labelled cells were also seen in the limb bud (LB) and in the region of the sympathetic ganglia (short and long arrows, respectively). (D) In a glancing longitudinal section of the somites at the level of the forelimb through an embryo incubated for $24 \mathrm{~h}$; Dil-labelled cells were seen in the rostral ( $R$ ) but not the caudal (C) portion of the somite (arrows). (Rostrocaudal level of section: $A$ and $B=$ somite 11, $\mathrm{C}=$ somite 10 . A-D: scale bar $=100 \mu \mathrm{m}$ ).

Fig. 3. Sections through embryos injected at E9.5, E10 and E10.5. (A) Longitudinal section at the level of the forelimb through an embryo injected at E9.5 and incubated for $24 \mathrm{~h}$; Dil-labelled cells were seen in the condensing dorsal root ganglia (DRG). (B) Similar section through an embryo injected at E10 and incubated for $12 \mathrm{~h}$; Dil-labelled cells were seen in the dorsal root ganglia (DRG; short arrows) and along the dorsolateral pathway (long arrows).

(C) Transverse section of an embryo injected at E10.5 and incubated for $12 \mathrm{~h}$; Dil-labelled motor root fibers (arrow) and what may be a ventral root sheath cell (arrow head) were the only labelled objects observed external to the neural tube. (Rostrocaudal level of section: $C=$ somite 10 . A: scale bar $=125 \mu \mathrm{m}$; B: scale bar $=40 \mu \mathrm{m}$; C: scale bar $=100 \mu \mathrm{m})$.

\section{Pathways of neural crest cell migration inferred from DiI-labelling}

Based on the pattern of Dil-labelling described above at the level of the forelimb, we infer that neural crest emigration from the neural tube begins at E8.5 and continues through E10. Labelled cells appear to migrate along the dorsolateral pathway throughout this period (Fig. 4B-D). Migration along the ventral pathways appears to occur in two overlapping phases. The first phase occurs between E8.5 and E9.5. Labelled cells leave the neural tube and enter the dorsal wedge, a cell-free space adjacent to the neural tube, ectoderm and dorsal somite (Fig. 4A). From this site, individual labelled cells move through the rostral sclerotome adjacent to the dermamyotome, to populate the sympathetic ganglia and the adrenergic derivatives around the dorsal aorta (Fig. 4B and C). Starting at E9 and proceeding through $\mathrm{E} 10$, a second phase of migration takes place; labelled cells appear as a thin stream along the lateral surface of the neural tube, opposite the rostral half of the sclerotome (Fig. 4C and D). Later, these cells protrude into the sclerotome, where they condense into dorsal root ganglia. In addition, other cells appear to migrate along the neural tube, then move laterally through the rostral sclerotome into the limb bud. Based on their final location, neural tube
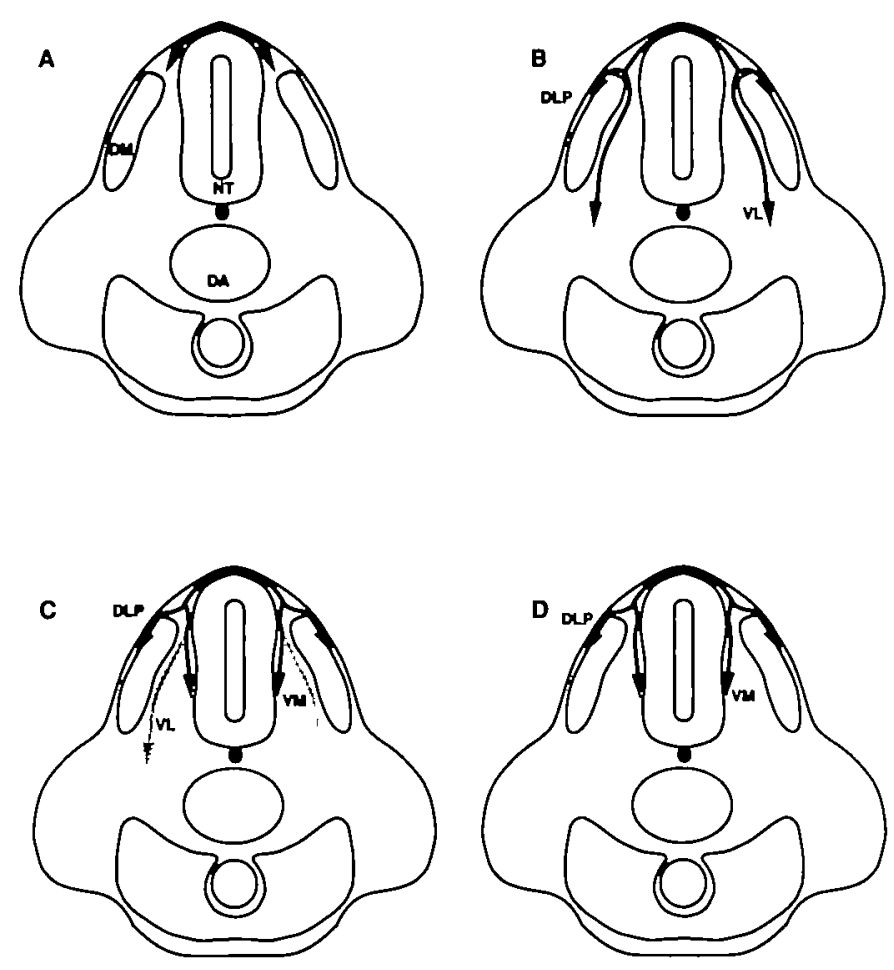

Fig. 4. Schematic representation of the pathways of trunk neural crest cell migration at the level of the forelimb. (A) At approximately E8.5, neural crest cells emerge from the dorsal portion of the neural tube (NT) into the cell-free space bordered by the neural tube, the somite and the ectoderm. (B) At E9, neural crest cells can be seen along two pathways: (1) a dorsolateral pathway between the dermamyotome and the epidermis (DLP), and (2) a ventral pathway between the neural tube and the dermamyotome. The ventral pathway consists of two overlapping phases of migration. Initially, neural crest cells appear only under the medial surface of the dermamyotome (DM). These early migrating cells extend along the ventrolateral portion (VL) of the sclerotome to the level of the dorsal aorta (DA). (C) By E9.5, migrating neural crest cells are apparent along the lateral surface of the neural tube (NT) (i.e. the ventromedial (VM) portion of the sclerotome). A few neural crest cells are present along the ventrolateral portion (VL) of the sclerotome, as well as in the region of the ventral derivatives. In addition, neural crest cells migrate along the dorsolateral pathway (DLP). (D) By E10, neural crest cells no longer migrate along the ventrolateral portion (VL) of the ventral pathway, but are present along the ventromedial portion (VM) and the dorsolateral pathway (DLP).

origin, and association with the ventral motor axons, the cells that migrate into the limb bud are likely to be Schwann cells. Labelled cells are not found in ventral derivatives in embryos labelled with DiI at E9.5 or later. DiI-labelled cells are found in progressively more dorsal derivatives with later injections, suggesting that neural crest cells contribute to their derivatives in a ventral-to-dorsal order (Fig. 5). Neural crest cell emigration from the neural tube appears to be complete by E10.5. 

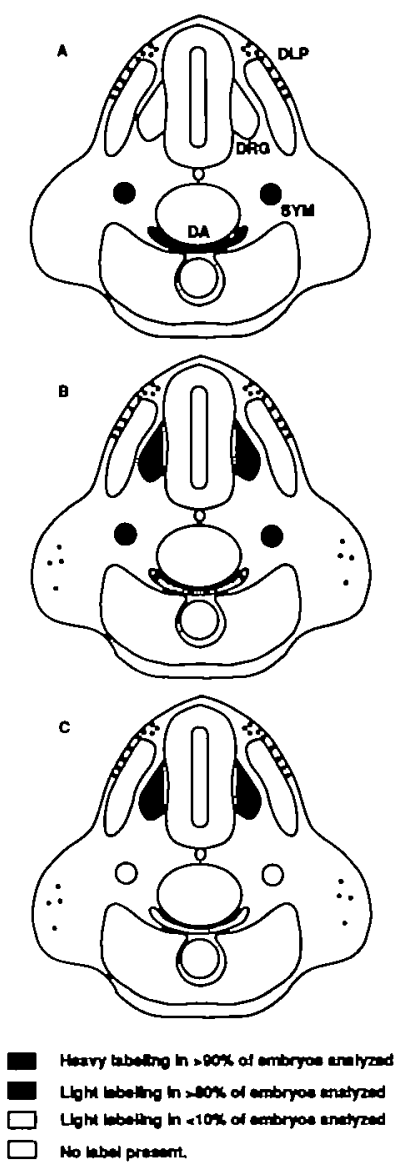

Fig. 5. Schematic representation of the appearance of Dillabelled cells in the region of the forelimb after injection at progressively later stages. (A) In embryos injected at E8.5, labelled cells were observed along the ventral pathway in the region of sympathetic ganglia (SYM) and the dorsal aorta (DA). Labelled cells were also observed along the dorsolateral pathway (DLP). (B) Embryos injected at E9 possessed a few labelled cells in the sympathetic ganglia and around the dorsal aorta. In addition, labelled cells were found in the dorsal root ganglia (DRG) and in the forelimb (LB), as well as along the dorsolateral pathway.

(C) Embryos injected at E10 contained labelled cells in the dorsal root ganglia, but not in any ventral locations. Labelled cells were still present along the dorsolateral pathway.

\section{Discussion}

We have adapted a vital dye approach for studying the pathways of neural crest cell migration in the trunk of the mouse embryo. At the level of the forelimb (somites 8-12), we observed that DiI-labelled neural crest cells initially emigrated from the neural tube into a cell-free space, the dorsal wedge, bordered by the dorsal neural tube, the adjacent somite and the ectoderm at E8.5 (15 somite stage). This observation is consistent with previous ultrastructural studies, which demonstrate that neural crest cells first appear on the dorsal surface of the neural tube 2-4 somites rostral the most recently formed somite, and that emigration from the neural tube occurs in a rostral-to-caudal sequence in the trunk
(Rawles, 1947; Erickson and Weston, 1983; Erickson, 1986). Neural crest cells appear to migrate in two primary directions away from the dorsal surface of the neural tube: (1) ventrally within the rostral portion of the somite and (2) dorsolaterally between the dermamyotome and the epidermis. DiI-labelled cells following the dorsolateral pathway first become apparent at E9 and were observed along this route until E10.5. This result contrasts with previous ultrastructural studies suggesting that neural crest cells do not appear on the dorsolateral pathway until after E10 (Erickson and Weston, 1983). Because the migrating DiI-labelled cells were closely associated with the dermamyotome, they may not have been sufficiently distinct to identify by ultrastructural criteria; thus, it is not surprising that they were missed in earlier studies. Our results are consistent with experiments involving epidermal/ mesodermal co-cultures from pigmented and non-pigmented mice (Rawles, 1947; Mayer, 1973), which suggested that melanoblasts were associated with the dermamyotome as early as E8.5.

By observing the pattern of labelled cells following DiI injection at progressively later stages, we inferred that there were two phases of migration that take distinct trajectories through the ventral somite. An early ventrolateral pathway, which begins before E9 and apparently ends by E9.5, consists of cells in the sclerotome adjacent to the medial surface of the dermamyotome. This group of cells extends ventrally to the level of the sympathetic ganglia and the dorsal aorta. The later ventromedial pathway is apparent after E9 and continues through E10.5. Cells following this route appear initially as a thin strand of cells juxtaposed to the lateral surface of the neural tube. At later stages, they protrude into the rostral sclerotome, contributing to both the condensing dorsal root ganglia and the Schwann cells along motor axons.

In addition to labelled cells within the trunk, a small population of neural crest cells were observed within the forelimbs following injections at E9 to E9.5. Although their prospective fate is unknown, it is possible that these labelled cells give rise to the Schwann cells of the forelimb. In avians, Schwann cells are thought to migrate in advance of the ventral motor axons, perhaps helping to guide them from the neural tube to the wing bud (Keynes, 1987; Loring and Erickson, 1987; Noakes et al. 1988). Consistent with this hypothesis, we observed DiI-labelled cells both in the limb and in the trunk prior to motor axon outgrowth. Because these cells do not appear until approximately E9.5, they most likely reach the limb by migrating in the later ventromedial phase along the neural tube, through the ventral portion of the sclerotome, and into the limb bud; although, it is possible that some of these cells are ventral root sheath cells, which emerge from the ventral portion of the neural tube in avians (Lunn et al. 1987), these ventral root cells do not appear to migrate extensively. Therefore, it is unlikely that they contribute to the cells in the forelimb.

Previous studies suggested that mouse neural crest cells migrating along the ventral pathway penetrate 
both the rostral and caudal halves of the somitic sclerotome (Erickson and Weston, 1983). However, no firm conclusions could be drawn, because the unlabelled neural crest cells within the sclerotome could not be distinguished from sclerotomal cells. In the present analysis, the DiI label provides an unambiguous assay; DiI-labelled cells on the ventral pathway of mouse embryos appear only in the rostral portion of the somite.

From a number of experiments examining the relationship between the basal lamina and neural crest migration (Sternberg and Kimber, 1986; Martins-Green and Erickson, 1986; Sternberg and Kimber, 1986a,b), it was inferred that neural crest emigration ceases between 16 and 30 somites rostral to the most recently formed somite. In the present experiments, a more accurate estimate is provided by injecting DiI into progressively older embryos and determining the rostrocaudal level at which no neural crest cells are observed. Based on this approach, we estimate that neural crest cells cease emigrating from the neural tube 23-27 somites rostral to the most recently formed somite. Because trunk neural crest cells in the mouse may disperse rostrocaudally as they do in avian embryos (Teillet et al. 1987), this may be a slight overestimate. That is, labelled neural crest cells from the 'younger' caudal regions may migrate rostrally to contribute to neural crest derivatives at 'older' levels, making it appear that the emigration continues for slightly longer than is actually the case.

Only those neural crest cells that are premigratory at the time of injection should be labelled by DiI. Therefore, a direct assay for the order in which neural crest cells populate their derivatives is obtained by determining the derivatives that do or do not contain labelled cells after injecting DiI at progressively later stages. Following injection of DiI into younger embryos (E8.5), labelled cells are observed in the sympathetic ganglia and around the dorsal aorta. Embryos receiving injections at slightly later stages (E9) possess labelled cells in these ventral derivatives, as well as in the dorsal root ganglia and the Schwann cells. Embryos injected with DiI at still later stages (E10) contain labelled cells in the dorsal root ganglia, but not in any ventral locations. These data, summarized in Table 1 and Fig. 5, suggest that the derivatives along the ventral pathways were populated in a ventral-to-dorsal order, as is suggested for avian embryos (Weston and Butler, 1966; Serbedzija et al. 1989). In contrast to our analysis of avians (Serbedzija et al. 1989), labelled cells are found on the dorsolateral pathway in mouse embryos at all stages during the period of migration.

The pattern of trunk neural crest cell migration observed for mouse has a number of similarities to those described in avians and rats. In all three species, neural crest cells initiate migration in a rostrocaudal wave. Along the ventral pathways, neural crest cells migrate exclusively through the rostral portion of each somite (Rickmann et al. 1985; Bronner-Fraser, 1986; Erickson et al. 1989; Serbedzija et al. 1989), suggesting that similar mechanisms of segmentation in the periph- ery may exist in the three species. Furthermore, in both chicken and mouse, neural crest cells migrating along the ventral pathway appear to populate their derivatives in a ventral-to-dorsal order (Weston and Butler, 1966; Serbedzija et al. 1989). In contrast to avians, where neural crest cells appear to move uniformly through the rostral portion of the sclerotome, relatively few neural crest cells in the mouse appear to invade the entire sclerotome. Instead, neural crest cell migration along the ventral pathway apparently occurs in two overlapping phases. An early migrating group of cells primarily moves along the medial surface of the dermamyotome facing the sclerotome, with a few cells within the sclerotome; a later group of cells migrates along the lateral surface of the neural tube. A similar pattern can be seen in the micrographs of rat embryos published by Erickson and colleagues using HNK-1 immunoreactivity as a marker for rat neural crest cells (Erickson $e t$ al. 1989).

DiI-labelling has several advantages as a marker for migrating neural crest cells in mice. DiI-labelled cells are easily distinguishable from unlabelled cells along neural crest pathways. Although wheat germ agglutinin conjugates can be used to mark premigratory neural crest cells within the neural folds at very early stages (Smits-van Prooije et al. 1986), they are not useful after the folds fuse to form the neural tube. In contrast, intraluminal injection of DiI following neural tube closure allows labelling of neural crest cells at a variety of developmental stages. As with any labelling technique of this type, a potential problem with our approach using DiI is that it may fail to label all of the premigratory neural crest cells. Because no reliable alternative markers such as neural crest-specific antibodies are available for the mouse, it is not possible to determine the proportion of neural crest cells that fail to become DiI-labelled. In light of the consistency from animal-to-animal in the positions and numbers of DiIlabelled cells, we do not feel that our experiments were hampered by this potential complication.

In summary, by injecting DiI into the lumen of the neural tube, we have been able to preferentially label premigratory neural crest cells. By performing injections at a variety of stages, it has been possible to determine the pattern and timing of neural crest migration in the mouse embryo. A comparison with similar experiments in the chicken embryo (Serbedzija et al. 1989) suggests that many features of neural crest migration are common to the two species. The most notable of these are the metameric organization of the ventral pathway of migration, and the ventral-to-dorsal order in which the neural crest derivatives are populated. There are also some significant differences; in mouse, the ventral pathway is segregated into two phases of migration, and the dorsolateral pathway becomes populated much earlier in development. Comparative studies of both the commonalities and differences between the avian and mouse migration pathways may provide important insights into the mechanisms of neural crest cell migration. For example, differences in the microenvironments through which the cells migrate 
should implicate molecular and physical mechanisms that influence cell movement. In the past, such comparative studies have been hampered by the lack of an adequate marker for neural crest cells in the mouse and by the difficulty of manipulating mouse embryos in utero. The DiI-labelling technique surmounts the first limitation, and the recently developed exo utero technique for manipulating mouse embryos (Muneoka et al. 1986) offers a means to overcome the second. By combining an exo utero approach with DiI-labelling, we hope to perform the needed long-term experiments on neural crest cell migration and differentiation in the mouse.

We thank Scott Burgan for excellent technical assistance and Mark Cooper for suggesting the use of the sucrose solution. This work was supported by USPHS Grant HD25138 and the March of Dimes Birth Defects Foundation.

\section{References}

Bronner-Fraser, M. (1986). Analysis of the early stages of trunk neural crest migration in avian embryos using the monoclonal antibody HNK-1. Devl Biol. 115, 44-55.

Chan, W. Y. and TaM, P. P. L. (1988). A morphological and experimental study of the mesencephalic neural crest cells in the mouse embryo using wheat germ agglutinin-gold conjugates as the cell marker. Development 102, 427-442.

Chibon, P. (1967). Marquage nucleare par la thymidine tritiee des derives de la crete neurales chez l'Amphibien Urodele. Pleurodeles waltlii Michah. J. Embryol. exp. Morph. 18, $395-441$.

Erickson, C. A. (1986). Morphogenesis of the neural crest. In Developmental Biology: A Comprehensive Synthesis, vol. 2 (ed. L. W. Browder) 481-543. New York: Plenum Press.

Erickson, C. A., Loring, J. L. ANd Lester, S. M. (1989).

Migratory pathways of HNK-1 immunoreactive neural crest cells in rat embryo. Devl Biol. 134, 112-118.

ERickson, C. A. AND Weston, J. A. (1983). An SEM analysis of neural crest migration in the mouse. J. Embryol. exp. Morph. 74, 97-118.

Gesink, A. F., Poelmann, R. E., Smits-Van Prooute, A. E. and Vermeu-KeErs, C. (1983). The cell surface coat during closure of the neural tube, as revealed by concanavalin $A$ and wheat germ agglutinin. J. Anat. 125, 418-419.

HARRISON (1935). Heteroplastic grafting in embryology. The Harvey Lectures 29, 116-157.

Holley, J. A. AND Yu, R. K. (1987). Localization of glucoconjugates recognized by the HNK-1 antibody in mouse and chick embryos during early neural development. Dev. Neurosci. 9, 105-119.

HoNiG, M. G. AND Hume, R. I. (1980). Fluorescent carbocyanine dyes allow living neurons of identical origin to be studied in longterm cultures. J. Cell Biol. 103, 171-187.

Horstadius, S. (1950). The Neural Crest. Oxford Univ. Press, London and New York.

KEYNES, R. J. (1987). Schwann cells during development and regeneration: leaders or followers. Trends in NeuroSci. 10, 137-139.

Krotoski, D., Fraser, S. and Bronner-Fraser, M. (1988). Mapping of neural crest migration in Xenopus laevis embryos using inter- and intra-specific cell markers. Devl Bıol. 127, 119-132.

Le Douarin, N. M. (1973). A biological cell labelling technique and its use in experimental embryology. Devl Biol. 30, 217-222.

Le Douarin, N. (1982). The Neural Crest. Cambridge, UK Cambridge University Press.

LoRING, J. P. AND ERICKSON, C. A. (1987). Neural crest migratory pathways in the trunk of the chick embryo. Devl Biol. 121, 220-236.

Lunn, E. R., Scourfield, J., Keynes, R. J. and Stern, C. D.
(1987). The neural tube origin of ventral root sheath cells in the chick embryo. Development 101, 247-254.

Martins-Green, M. and Erickson, C. A. (1986). Development of neural tube basal lamina during neurulation and neural crest cell emigration in the trunk of the mouse embryo. J. Embryol. exp. Morph. 98, 219-236.

MAYER, T. C. (1973). The migratory pathway of neural crest cells into the skin of mouse embryos. Devl Biol. 34, 39-46.

Muneoka, K., Wanek, N. and Bryant, S. V. (1986). Mouse embryos develop normally exo utero. J. exp. Zool. 239, 289-293.

NEw, D. A. T. (1973). Studies on mammalian fetuses in vitro during the period of organogenesis. In The Mammalian Fetus In Vitro (ed. C. R. Austin) 15-65. London: Chapmen and Hall.

New, D. A. T. (1977). Whole-embryo culture and the study of mammalian embryos during organogenesis. Biol. Rev. 53, $81-122$.

Noakes, P. G., Bennet, M. R. and Stratford, J. (1988). Migration of Schwann cells and axons into developing chick forelimb muscle following removal of either the neural tube or the neural crest. J. comp. Neuro. 277, 214-233.

Rawles, M. E. (1947). Origin of pigment cells from the neural crest in the mouse embryo. Physiol. Zool. 20, 248-266.

Rickmann, M., Fawcett, J. W. and Keynes, R. J. (1985). The migration of neural crest cells and the growth of motor axons through the rostral half of the chick somite. J. Embryol. exp. Morph. 90, 437-455.

Sadaghiani, B. and Thiebaud, C. H. (1987). Neural crest development in the Xenopus laevis embryo studied by interspecific transplantation and scanning electron microscopy. Devl Bio. 124, 91-110.

SADLER, T. W. (1979). Culture of early somite mouse embryos during organogenesis. J. Embryol. exp. Morph. 49, 17-25.

Sadler, T. W. AND NEw, D. A. T. (1981). Culture of mouse embryos during neurulation. J. Embryol. exp. Morph. 66, $109-116$.

Serbedzua, G. N., Bronner-Fraser, M. and Fraser, S. E. (1989) $A$ vital dye analysis of the timing and pathways of avian neural crest cell migration. Development 106, 809-819.

Sims, P. J., Waggoner, A. S., Wary, L. H. and Hoffman, J. F. (1974). Studies on the mechanısms by which cyanine dyes measure membrane potential in red blood cells in phosphatidylcholine vesicles. Biochemistry 13, 3315-3330.

Smits-Van Prooue, A. E., Poelmann, R. E., Dubbeldam, J. A., Mentink, M. M. T. and Vermeis-Keers, C. (1986). Wheat germ agglutinin-gold as a novel marker for mesectoderm formation in mouse embryos cultured in vitro. Stain Technology 61, 97-106.

Sternierg, J. and Kimber, S. J. (1986a). Distribution of fibronectin, laminin, and entactin in the environment of migrating neural crest cells in early mouse embryos. J. Embryol. exp. Morph. 91, 267-282.

Sterngerg, J. AND KIMBER, S. J. (1986b). The relationship between emerging neural crest cells and basement membrane in the trunk of the mouse embryo; a TEM and immunocytochemical study. $J$. Embryol. exp. Morph. 98, 251-286.

TAN, S. S. AND Morriss-KaY, G. M. (1986). Analysis of cranial neural crest cell migration and early fates in postimplantation rat chimeras. J. Embryol. exp. Morph. 98, 21-58.

Teillet, M. A., Kalcheim, C. and Le Douarin, N. M. (1987). Formation of the dorsal root ganglia in the avian embryo: segmental origin and migratory behavior of the neural crest progenitor cells. Devl Biol. 120, 329-347.

VINCENT, M. AND THIERY, J. P. (1984). A cell surface marker for neural crest and placodal cells: Further evolution in peripheral and central nervous system. Dev/ Biol. 103, 468-481.

WESTON, J. A. (1963). An autoradiographic analysis of the migration and localization of trunk neural crest cells in the chick Devl Biol. 6, 279-310.

WESTON, J. A. (1970). The migration and differentiation of neural crest cells. Adv. Morphog. 8, 41-114.

Weston, J. A. AND BUTLER, S. L. (1966). Temporal factors affecting localization of neural crest cells in the chicken embryo Devl Biol. 14, 246-266. 